\title{
APPLICATION OF GAMIFICATION AS A DRIVER FOR BETTER BUSINESS PERFORMANCES: CASE OF GROUPER
}

\author{
Nina Angelovska ${ }^{1, *}$ and Sasho Josimovski ${ }^{2}$ \\ ${ }^{1}$ Macedonian E-commerce Association \\ Skopje, North Macedonia \\ ${ }^{2}$ Faculty of Economics \\ University "Ss. Cyril and Methodius", Skopje, North Macedonia \\ DOI: 10.7906/indecs.19.1.11 \\ Received: 11 December 2020. \\ Regular article \\ Accepted: 15 March 2021.
}

\begin{abstract}
Gamification appeared in the realm of marketing and became popular after 2010. The use of gaming applications has become a significant trend in the business world, as an opportunity for alternative interaction with users, particularly applicable in e-commerce. The goal of this study is to examine the effects of using gamification on increasing the customer database and sales or identifying the ability of gamification in turning visitors to users and users to customers, as well as the effects on event promotion and awareness. The research instrument used in this study to develop the game "Birthday slot machine" is the D6 design framework for gamification. Data used in this study is collected for a period of 15 days when the game was implemented, starting January 15 to January 30, 2014, from Grouper's customer and sales database. Descriptive analysis and T-test are used to analyze the effects of gamification application. The findings showed that the application of a well-structured game was effective, resulting in an increase in the number of new customers during the game by $318 \%$, an increase in monthly sales by $45 \%$, and well-created awareness for the company and event that was promoted.
\end{abstract}

\section{KEY WORDS}

gamification, e-commerce, group buying, 6D framework, North Macedonia

\section{CLASSIFICATION}

JEL: $\quad$ M39 


\section{INTRODUCTION}

Advanced technologies enable the use of new marketing tools to promote and increase customer engagement. Using a game element in the context of doing business or achieving appropriate business goals is a worldwide trend and is called gamification. Gamification has become a buzzword, widely used by the mass media to describe the addition of game mechanics to serious business activities. Gamification can be a challenge for managers as a tool for achieving business goals such as: increasing the number of users, stimulating and motivating employees to sell, increase sales, strengthen the brand, solve problems, increase customer engagement etc. The use of gaming applications or so-called "Gamification" has become a significant trend in the business world as an opportunity for alternative interaction with users. The use of this tool is particularly applicable in e-commerce which challenges all traditional methods of work and opens up a wide range of subjects that organizations must consider. E-commerce is a huge field with lots of different business practices, ways to market products and reach customers. Simply defined, "electronic commerce is a system of online shopping and information retrieval accessed through networks of personal computers" [1; p.29]. Marketing is a broad field, which encompasses many different goals and disciplines. Kotler and Keller [2] define marketing management as "the art and science of choosing target markets and getting, keeping, and growing customers through creating, delivering, and communicating superior customer value". Managers and marketers today need to search for new ways to engage customers, communicate their brand and differentiate from competitors. One approach that has gained tremendous popularity after 2010 is gamification that changed not only marketing strategy, but also affected consumer behavior. It became a marketing tool that apart from aiming to boost sales and increase profit, also affects improvement in customer engagement, enhances product/brand identification and helps in building loyalty [3-6]. The rationale behind deploying video game elements in business context is that they have already captured the attention of millions of loyal players all over the world and in United States, about $58 \%$ of the population played video games [7]. When players engage the gamified environment, they willingly immerse themselves in virtual challenges for the purpose of achieving fun and play; elements deeply rooted in human beings: "Intrinsically motivated activities are those that the individual finds interesting and performs without any kind of conditioning, just by the mere pleasure of carrying them out" [8; p.114]. Increased engagement is claimed to have numerous benefits like improved performance and greater user satisfaction [9]. The basic mechanics of gamification are closely related to the mechanics of game design: addressing the human desire for socializing, learning, mastery, competition, achievement, status, altruism, self-expression, or closure [10]. Reeves and Read in their work meticulously maps game elements like avatars, leaderboards, leveling and reputation to general business processes [11]. Despite the large amount of hits on the topic, there is a dearth of coherent understanding on what kind of studies have been conducted under the term gamification, with which methods, what kinds of results they yield, and under which circumstances. Understanding whether gamification is effective is also a pertinent practical issue [3].

The goal of this study is to examine the effects of using gamification on increasing the customer database and sales, or identifying the ability of gamification in turning visitors to users and users to customers, as well as the effects on event promotion. To reach the goal this study uses a designed web application called "Birthday Slot Machine" introduced by Grouper in 2014, and evaluates the results achieved with its solution. The gamified solution in the 
form of a web application aimed to create engagement, increase brand awareness, reward existing customers, increase the number of customers, promote an event and increase sales.

The research questions are focused on:

1. Can application of gamification increase the number of users?

2. Can application of gamification increase sales?

3. How effective was the applied gamification for the promotion of the event and awareness, word-of-month and buzz?

The remainder of the article is organized as follows. Section 1 presents the literature review on gamification. Section 2 provides a description of the model of Grouper. Section 3 gives methodology and data. Section 4 presents empirical analyses with the results regarding the effects of the application of gamification. The last section gives concluding remarks.

\section{THEORETHICAL BACKGROUND}

Games are an expression of some basic parts of human nature and are an integral part of all societies. The history of games dates back to ancient times [12]. Traditional marketing authorities emphasize that marketing is about identifying and meeting human and social needs $[2,13]$. The purpose of marketing is to understand the need of the customer [13], which will be expressed in the customer who has a desire to buy as result. Throughout history, marketers have used games to use one of the most powerful behavioral motivators. Managers and marketers must look for new ways to engage their customers, communicate their brand, and stand out from the competition by creating a competitive advantage. Gamification may be a new term, but the idea of using thought and game mechanics to solve problems and engage audiences is not new [5]. The Internet has opened up new possibilities for introducing game elements into business activities. Gamification is becoming a significant trend that has emerged since 2010 and has significantly changed the way businesses communicate and interact with their customers. The term gamification is coined by computer programmer/game designer Nick Felling in 2002, and was defined as the use of game elements and mechanics in non-game context [14]. Huotari and Hamari [15] redefine the definition of gamification in terms of service marketing experiences as: "a process of improving services through gaming experiences to support overall value creation". This definition begins with the goal of gamification, instead of defining only its use as a tool in a business context. Gamification is almost universally accepted by all authors as simply defined as the use of game design elements in a serious or not-for-play context. This practice does not mean that the whole game should be designed, but assumes the use of only those elements of the game that are considered useful for the given context [14]. It can be used by almost all companies as well as non-profit organizations and by the government, all in order to achieve various goals. Gamification revolutionizes business thinking and practices and according to Zicherman and Linder [6] game mechanics integrated with business strategy, serve as an invaluable change agent for the management to motivate employees and customers. Regardless of various definitions of gamification, its main purpose is to create fun, to stimulate significant motivation, to encourage engagement.

For the purposes of this article, gamification is defined as designing and applying game elements in a business activity created to achieve a company's predetermined goals.

Hamari [3] provides a literature review of empirical studies on gamification showing that the appearance of the term "gamification" in article titles has been increasing even more rapidly than general search hits suggesting that gamification is becoming a more popular subject for academic inquiry. 
Gamification is the process of introducing game mechanics to business software and is defined, e.g., as "[applying] the mechanics of gaming to non game activities to change people's behavior. When used in a business context, gamification is the process of integrating game dynamics (and new game mechanics) into a website, business service, online community, or marketing campaign in order to drive participation and engagement" [16]. Three key relationship marketing concepts are relevant in the gamification context: engagement - "high relevance of brands to consumers and the development of an emotional connection between consumers and brands" [17], brand loyalty - "the relationship between relative attitude and repeat patronage" [18] and brand awareness - "the rudimentary level of brand knowledge involving, at the least, recognition of the brand name" [19]. Engagement in particular is often mentioned as the main goal of gamification [20-22].

Gamification is an emerging marketing discipline that provides a means of influencing the behavior of people online. It borrows key concepts from a number of related areas, including game design, customer loyalty programs, behavioral economics, and community management.

\section{THE MODEL OF GROUPER}

The business model of daily deal web sites also called group buying was introduced in 2008 by the leader in the industry Groupon from Chicago. In this sense, the new business model for group discounts for daily deals can be considered as a new type of electronic intermediary. This business model is a mediation between retailers and consumers in order to meet and trade online. It supports and coordinates the trading processes between retailers and customers through various functions. Daily deal sites act as intermediaries between the merchants and the end customers, by selling discounted deals in the form of coupons. Companies get promotion of their business's product/services while customers get great discounts via deals for new things to discover in their city. Daily deal sites bring hundreds of new customers to the doors of the companies and for return get a share of the price of each sold coupon. Grouper was launched in January 2011 as the first daily deal site on the Macedonian market and holds the leading position in the industry with $40 \%$ of the e-commerce market share in Republic of Macedonia in 2013 [23, 24]. Furthermore, it was announced to be the best ecommerce web site in 2013 in the country [25]. Its creative culture and use of new trends such as gamification are part of its marketing strategy. Grouper practiced game mechanics to reach different company goals. It launched a Facebook app called "Sell your friend via Grouper Deal" in 2012 to familiarize users with the constituent parts of its deals and create brand awareness and engagement. For its 3rd birthday celebration in 2013 it launched a deal selling scratch tickets where customers could win free coupons for deals or get a free drink at the celebration [23]. The new business model of group buying through daily deals, launched by Groupon, has sparked worldwide interest and has quickly spread through its clones in many countries around the world. In the Republic of Macedonia, this concept was introduced by Grouper, and then the concept is applied by other group buying websites.

By playing the intermediary role in group purchasing activities, Gruper is responsible for coordinating the work during the entire process, including initiating, negotiating, arranging, executing and most importantly satisfying both sides, companies and end-customers.

\section{METHODOLOGY AND DATA}

As one of the most commonly used designs in the field of business, case study is used in this study as a research design. Defining a strategy for gamification implementation that will best fit into effectively achieving the company's goals is a challenging task. Research instrument 
used in this case study to develop the gamification system is the D6 design framework for gamification, proposed by Werbach and Hunter [26; p.86]. The choice of this framework, as a method, is based on the detail of the model and its scientific support. The steps of the D6 model are: 1. Define business objectives; 2. Delineate target behaviors; 3. Describe your players; 4. Device activity loops; 5 . Do not forget the fun element; and 6. Deploy appropriate tools.

Defining business goals must be a starting position, because the introduction of the elements of the game in the business, above all, should lead to their achievement. Good understanding of the goals set, is a critical point for the effectiveness of the applied gamification. If the goals are well understood the game will be designed to achieve them. The value of the solution lies in the design aiming to achieve the determined business goals, instead of creating a solution that is just fun for the end-users.

Behavior Targeting suggests that it should be defined what exactly is required of users to do and how that behavior will be measured. Two ways are suggested to measure that behavior: points and winning states. However, they do not indicate how to motivate the participant to perform the desired behavior, but how to measure it.

Describing the participants in the game is important because they are the ones who will use the game system, so it is good to know what type of players they are. Better knowledge of the type of game-participants will help create the game system that will best suit them.

Activity loops move the action of the gamification system forward and give structure to the main aspects of the game. The concept is that one action provokes another, which in turn leads to the next action. There are two kinds of cycles to develop: engagement loops and progression loops. Engagement loops describe, at a micro level, what the players do, why they do it, and what the system does in response. Progression loops give a macro perspective on the player's journey. The goal is that users always know when they are doing something good and receive instant feedback to let them know they are progressing. Of course, it is not enough just to get feedback, because the participant in the game will not know whether s/he is moving forward or not and this requires progression loops that will give the impression that the experience changes with the movement of the participants through the game.

Fun elements are important, because having fun is the basis of games and gamification. The whole idea is to create a solution that is as fun as possible and engages the participants in the game as much as possible.

After defining and revealing all the previous steps, in the last step the appropriate tools are deployed to apply the most relevant and effective elements and structures in the game system. Any elements applied in any system does not mean that they will give a positive effect by default. Only the right use of the right elements can lead to success. In the sixth step, the pyramid of game elements, developed by Werbach and Hunter [26], can be used to best fit the goals, the targeted behavior, the types of participants in the game, the activity and the fun (Fig. 1). 

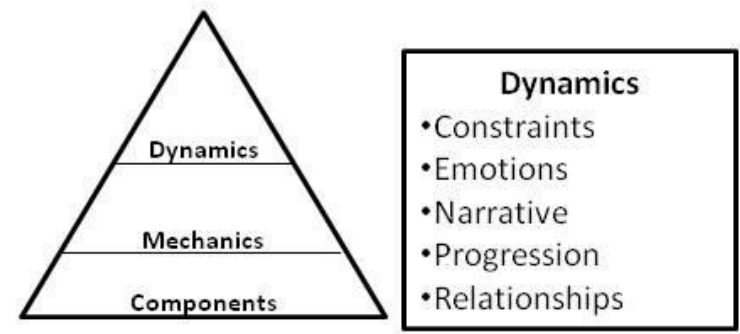

\begin{tabular}{|l|}
\hline \multicolumn{1}{|c|}{ Mechanics } \\
-Challenges \\
- Chance \\
- Competition \\
- Cooperation \\
- Feedback \\
- Resource \\
acquisition \\
- Rewards \\
- Transactions \\
- Turns \\
- Win states \\
\hline
\end{tabular}

Compoments

- Achievements

- Avatar

- Badges

- Boss fights

- Collections

- Combat

- Content unlocking

- Gifting

- Leaderboards

- Levels

- Points

- Quests

- Social graph

- Teams

- Virtual goods

Figure 1. Pyramid of game elements [26; p.78].

Data used in this study are collected from Grouper's customer and sales database. The data is collected in a period of 15 days when the game was applied starting from January 15 to 30, 2014.

Descriptive analysis and T-test are used to analyze the effects of the application of gamification by testing the following research hypotheses:

H1: The application of gamification can significantly increase the number of users.

$\mathrm{H} 2$ : The application of gamification can significantly increase sales.

H3: The application of gamification is an effective tool for promoting an event and creating engagement.

\section{GAME DESIGN AND RESULTS OF THE APPLICATION OF GAMIFICATION IN GROUPER}

"Birthday Slot Machine" is a web application created on the occasion of the forth birthday of the company, that traditionally celebrates its years of existence, bringing it closer to users and the offline world. The application of the gamification is toward achieving three goals: promoting an event - celebrating the fourth birthday, increasing the number of users and increasing sales (Grouper, 2014). For the needs of this research, the focus is put on the external perspectives and the presentation of the application of the slot machine as a gamified solution aiming to achieve the business goals set by the company.

The celebration event took place on February 1, 2014, and the duration of the game, which is subject to analysis, is in a period of 15 days from January 15 to January 30, 2014. The game was advertised through social media, email campaigns and banner ads on Grouper.mk. The game concept is a game of chance and is based on the luck of the participants who can randomly receive a prize. The game does not include competition between participants, statuses and points based on the skills and knowledge of the participants, so it awakens a sense of "having lucky". The algorithm of the game is created in such a way that every day an equal number of prizes are awarded during the duration of the game to the lucky winners.

The game is part of an integrated marketing campaign that starts online with the web application "Birthday Slot Machine" and ends with the physical presence of the winners and other participants at the birthday celebration of the company. The lucky winners in the game do not know what prize they have won, and in order to collect it, they need to come to the event where they will draw and pick-up their prize. The winners see only a list of prizes they 
could win, but do not know the exact one until they come to collect it. In order to investigate the application of gamification through the game "Birthday Slot Machine", the game is explained by applying the D6 framework for game design consisting of 6 steps.

(1) Defining business goals: Grouper has set three goals to achieve with this game and they are ranked according to the following schedule: promoting an event - the forth birthday of the company; increasing the number of users; and increasing sales. It is important that the goals are aligned with the mission of the company, so in that sense the main goal of the application is the promotion of the birthday event that the company traditionally organizes each year, which is open for all users while rewarding many of them. Furthermore, increasing the number of users is an obvious goal, as users are potential buyers/customers of the deals it offers. Finally, the third goal is to increase sales.

(2) Delineate target behaviors: Users are required to join the game by connecting with their current Grouper account via Facebook or by creating a new account via Facebook, all in order to collect more demographic data for each user via their their Facebook profile and additionally, because of the possibility the participant to share the game with his friends on Facebook. Each user, during the first login in the game, gets 3 spins on the slot machine. Behavior is measured through the active participation of users and through the number of winning spins that are published in the ranking list. To stimulate sharing the game with friends, each user can get a free spin by inviting a friend to join the game. Additionally, each user can get a spin by entering the coupon code from a purchased Grouper coupon from any deal, which stimulates additional sales and rewards buyers. After the spin, the user receives a notification to share the game on their Facebook profile, if desired.

(3) Description of the players: Participants in the game are all existing and potential Grouper users. According to demographics, the main target is online users aged 24 to 35. According to the desire for playfulness, the target of the game are online users who like interactions and games (socializers) and who want to explore (explorers).

(4) Device activity loops are defined in two phases: the engagement loops and progression loops. Engagement loops include motivation, action and feedback. The rewards given in the game, depending on the winning combination, are used as motivation for engagement. Table 1 shows the prizes for every winning option and the quantity of each prize. If the user wins, he gets a voucher code that he has to bring to the Grouper birthday event in order to collect the gift. If one user wins twice, he can give the winning voucher to a friend. All game players must connect their profiles via Facebook in order to play the game, thus once a day, the app posts a call to action with text to his timeline (if he gave permissions to the app when connecting). There are 2 ways for the player to get extra spins. The first is to request a free spin from a friend. In order to give a free spin the friend has to enter the app, give permissions and accept the invitation. The second is to get free spin with a coupon purchased during the previous month or s/he can buy a coupon at the moment and get a free spin by entering the coupon code. The first option creates word-of-mouth and buzz for the game and the second option is connecting the game directly with the sales.

Table 1. Prizes for the winners of the game [27].

\begin{tabular}{|l|l|c|}
\hline Winning combination & \multicolumn{1}{|c|}{ Prize } & Quantity of Prizes \\
\hline $\mathbf{3}$ x Grouper mascote & $\begin{array}{l}\text { Surprise Gift (Gifts from Partners of } \\
\text { Grouper, among which travel prizes for } \\
\text { weekend getaways, massages, spa } \\
\text { packages etc.) }\end{array}$ & 228 \\
\hline
\end{tabular}




\begin{tabular}{|l|l|c|}
\hline $\mathbf{3} \times$ Gs & $\begin{array}{l}\text { Grouper branded gifts (cups, pillows, t- } \\
\text { shirts) }\end{array}$ & 90 \\
\hline $\mathbf{3} \times$ wallets & $\begin{array}{l}\text { Grouper gift cards with various value } \\
\text { amounts for future purchases }\end{array}$ & 45 \\
\hline
\end{tabular}

(5) The fun element is the base of every game. A slot machine is a popular well-known game concept, and applying it in a non-gaming industry is intriguing for users. Additionally, through the design of the slots on the Slot Machine and the various winning combinations, a moment of fun and surprise for the users is created.

(6) Deployment of appropriate tools: Dynamics, mechanics and components are used in the deployment of game tools in order to create the whole solution.

(6.1) The selected dynamics in our game represent the concept of the Slot Machine as an already known type of game of chance.

- Limitations in this analyzed game are: the number of spins per user, which initially is 3 spins for each logged user; chance to win - each user to win a prize, i.e. if s/he wins a prize for the second time s/he can give it to a friend. An additional restriction is that the user must log in with his Facebook account to participate, which is a limitation for those who do not have a Facebook account.

- Emotions: The emotion created by this game is a sense of hope for a win before the spin, uncertainty during the spin, a surprise win and a desire to spin again.

- Narratives: The narrative is expressed through the text descriptions in the game and the design of the elements that are associated with the birthday of Grouper, and thus create a whole in the structure of the game.

- Progression: Because there are no levels in the application through which users can progress, the progression is expressed with a winning combination, i.e. if a user turns a winning combination he becomes the winner of a reward.

- Relationships: Users can invite their friends to get an extra spin on the slot machine, share the game on their Facebook profile and, in case of winning, share the win with their friends.

(6.2) Game mechanics are the more specific elements in the sense that they are aimed at more specific actions. The mechanics used in the game through the user scenario accompanied by a pictorial presentation of selected parts of the game are illustrated.

Each user gets 3 free spins on the slot machine. Each spin can be win or lose. (Chance). There are 3 possible winning combinations in the game; all three winning options are if the user gets 3 same slots (3xGrouper mascot; 3xWallets; and/or 3xGs).

The user scenario accompanied by screenshots from each game screen explains the game mechanics. The existing or potential user comes to the start screen (Fig. 2), as a result of a previously clicked link of the game banner ads, social media posts, links from friends or other ads where the game is promoted. The start screen provides basic information for the game, and at the same time invites the user to the birthday party (text in the bottom part). 


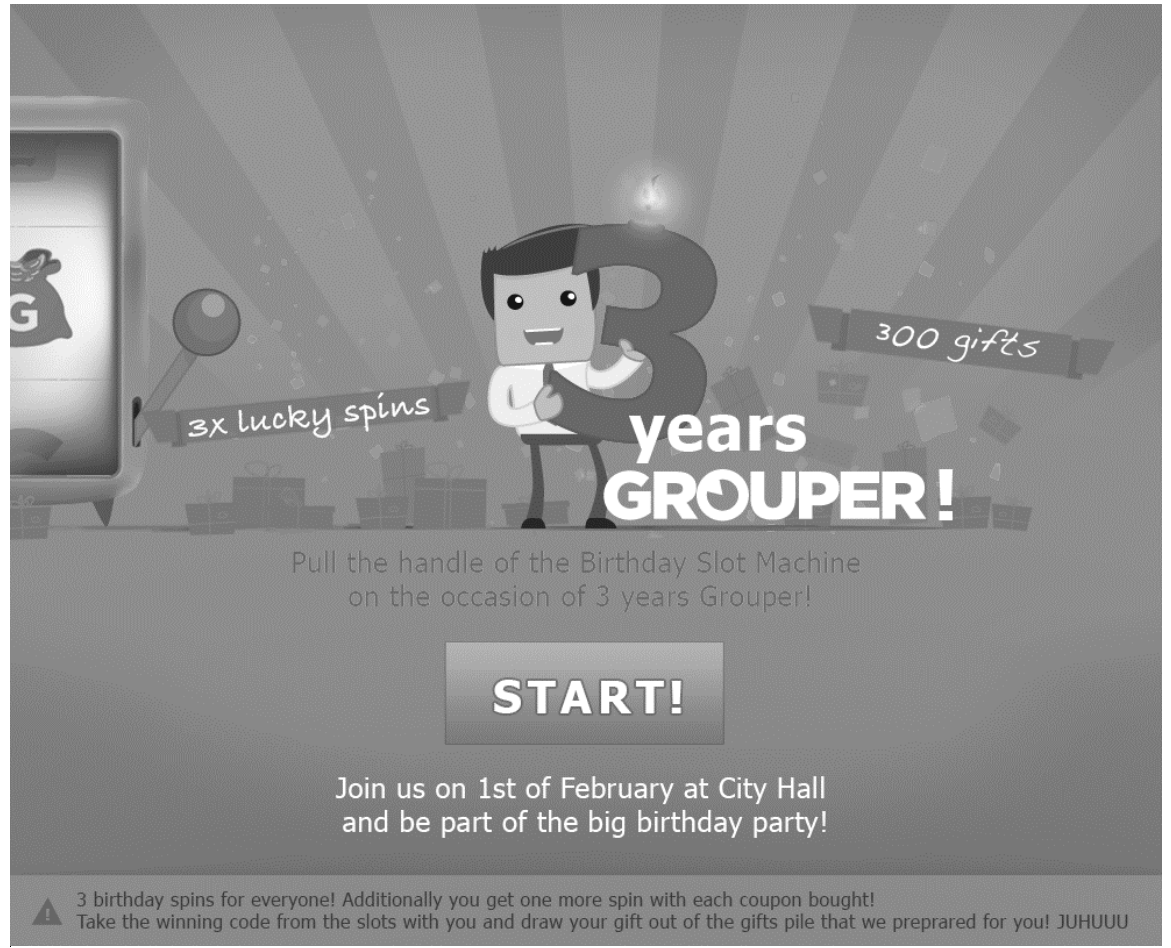

Figure 2. Screenshot: Start Screen [27].

The click of the button "Start" opens a pop up login form where the user has to connect his existing account via Facebook or create a new account via "Facebook Connect" button. Then the user is logged in and can start spinning. (Fig. 3)

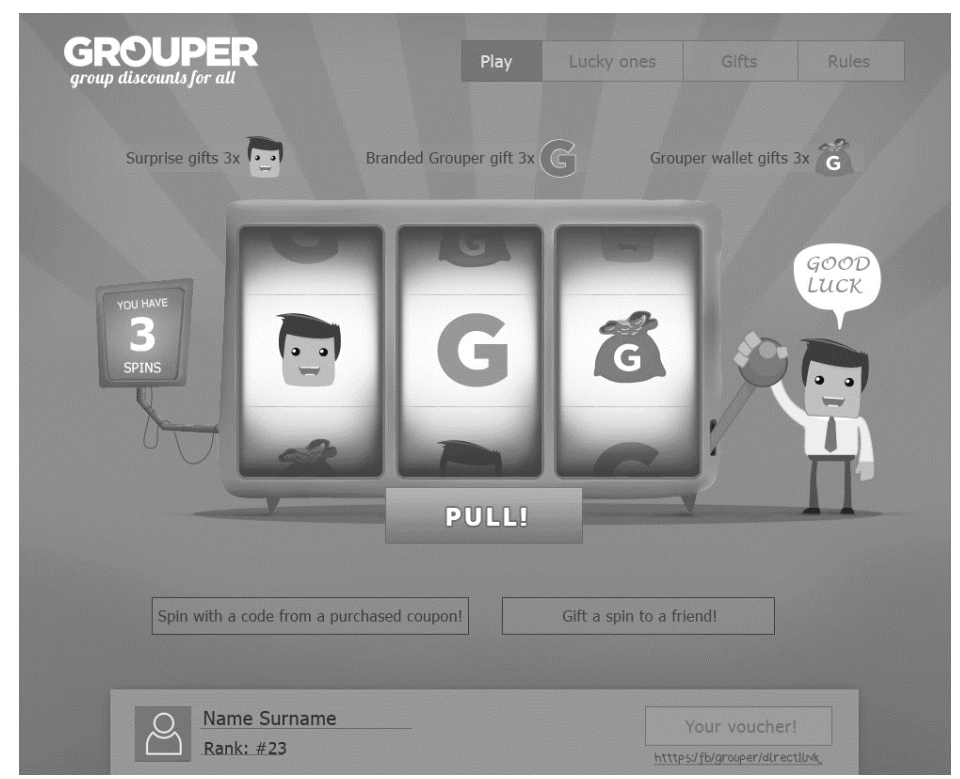

Figure 3. Screenshot: Logged in user ready to spin [27].

The outcomes of the spin can be a no-win combination and a win combination (three same slots). The winning combination can be either three mascots, three wallets or three Gs, and the user gets a pop-up notification for his win and a voucher code for collection of the prize. Fig. 4 shows the screen the user sees if he gets a winning spins for the second time. If the user is left with no spins he gets the call to action screen reminding him that he can purchase a coupon and get an additional spin. 


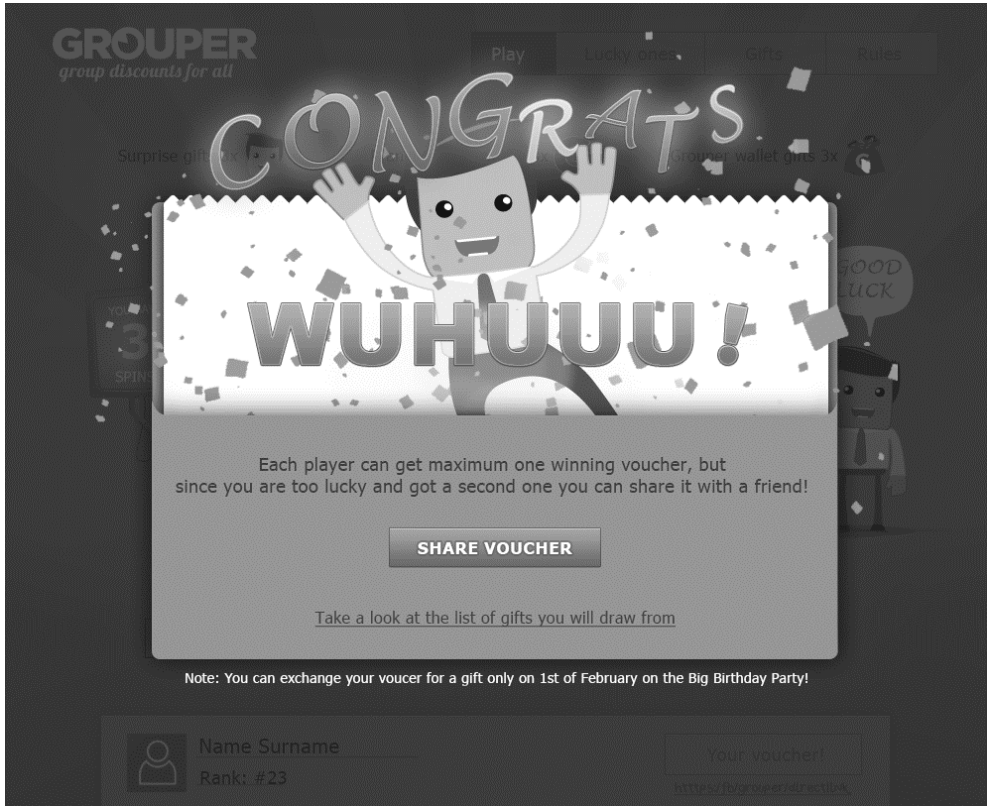

Figure 4. Screenshot: Second Win, Congrats Screen [27].

(6.3) Specific components or elements used in the interface of the game "Birthday Slot Machine" are the following:

- Achievement is receiving a reward that is random, i.e. based on the luck of the player.

- Avatar: After logging in, the image of the user appears in the web application. (Fig. 2)

- Gift: Players can give a spin to a friend.

- Claims: After a winning spin, the player receives a notification that $\mathrm{s} / \mathrm{he}$ has won along with information on how to collect the prize, i.e. an invitation to come to the birthday event to collect his prize. The winner of a prize is asked to present the winning code which is sent to him after the winning spin.

Having in mind the set of goals that Grouper wants to achieve with the web application "Birthday Slot Machine", the results for the set hypotheses are elaborated and presented below.

\section{H1: The application of gamification can significantly increase the number of users.}

The increase of new users in the past 12 months before the game was implemented was 1,200 new registered users on average per month [27]. The number of new registered users in January, when the game was launched, was 5,018, out of which 3,687 users were registered directly through the game. The total number of players in the game was 6,844 , out of which 1,826 connected their existing Grouper profiles with Facebook, allowing data collection in their profiles. Fig. 5 shows the growth of new users on a daily basis during January 2014. 


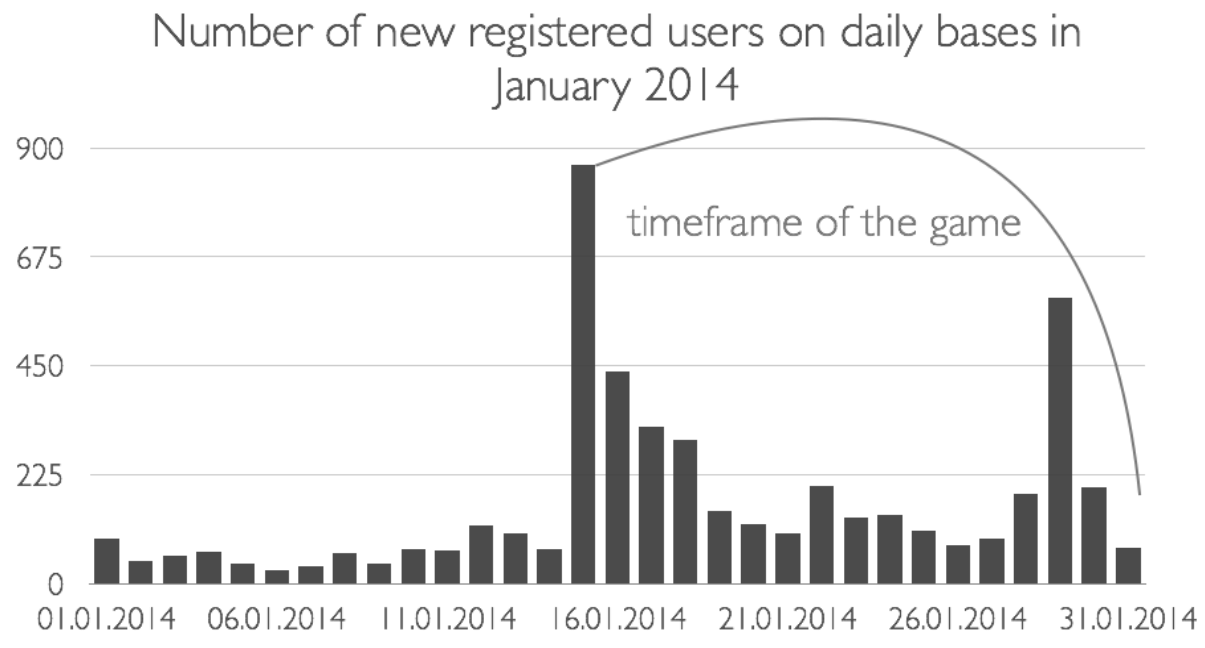

Figure 5. Report on the number of new users on daily basis in the period from 01.01.2014 to 31.01.2014 [27].

When setting the hypotheses, it is assumed that the application has no impact on the growth of the number of users and the number of daily sales. A t-test of two independent samples is used to test the hypothesis. To see the impact of the application, the number of new users during the game ( 15 days) is compared with the number of new users in the previous 15 days. The analysis of the t-test $(\mathrm{p}<0,05)$ showed rejection of the null hypothesis, i.e. there is a statistically significant difference in the number of new users in the two analyzed periods. It can be conclueded that the application of gamification can significantly increase the number of new users.

\section{H2: The application of gamification can significantly increase sales.}

The average number of coupons sold, on a monthly basis, in the previous 12 months before the game was 5,612 coupons. The number of coupons sold in January 2014 was 8,188, which resulted in an increase of over $45 \%$ compared to the monthly average [27]. More than 900 coupons sold in January were used to get additional Slot Machine spins from users, and 350 of them were purchased just before used for spins. This indicates a direct boost in sales from consumers who bought a coupon in order to get an extra spin, which means that $4,2 \%$ of coupons sold in January were due to applied gamification. The analysis assumes that there were no significant changes in the offer of deals on the site, i.e. that the offered deals were with the same pattern as the previous months since the average values of coupons and sales were calculated.

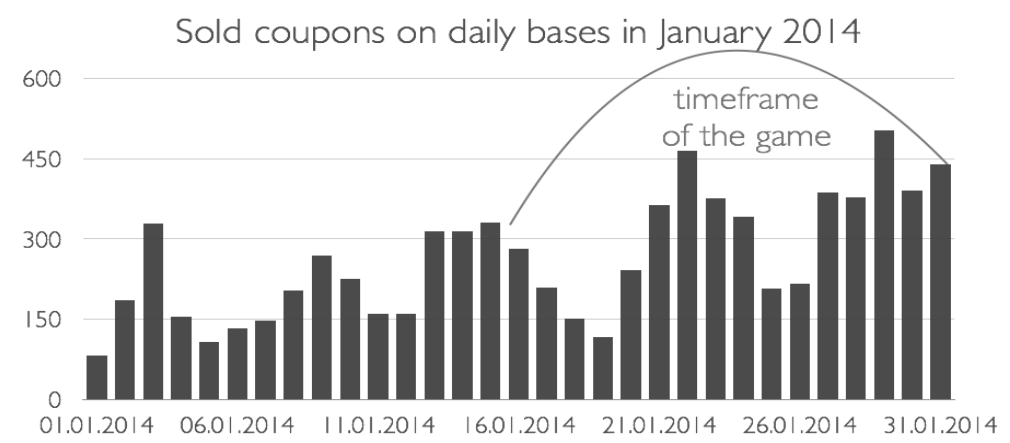

Figure 6. Report on the number of coupones sold on a daily basis in the period from 01.01.2014 to 31.01.2014 [27].

The same procedure for testing the hypothesis $(\mathrm{H} 2)$ is applied as in the case of testing the first hypothesis (H1). The analysis of the t-test $(p<0,05)$ showed the rejection of the null hypothesis, so 
it can be concluded that the application of gamification can significantly increase the number of sales.

\section{H3: The application of gamification is an effective tool for promoting an event and creating engagement.}

Since it is impossible to quantify this hypothesis, the effects of the application are considered through promotion of the event and awareness, word-of-mouth and buzz and the number of guests at the event. The application invited all users at the company's birthday party, regardless if they participated in the game or not. The winners of the game, 363 users, were also invited to the celebration event to collect their prizes. Grouper has sent reminder messages to all winners, reminding them on the date and location, as well as to bring their winning code to collect their prize. The event took place at a popular venue in the city center, with more than 1200 guests, including media representatives, business partners and customers. A total of 250 winners of the prizes from the conducted game were among the guests who collected their prizes, and the rest of the prizes that were not collected were distributed to other guests who shared content from the celebration on social media (Facebook, Instagram and Twitter) which contributed to increased word-of-mouth about the brand. The game itself proved to be viral and quickly spread among users as a result of content sharing by game participants. Players gave away and received free spins from friends, resulting in over 1000 spins received from friends. The company considers this event very successful, taking into account its attendance and the virality of social media [27].

\section{CONCLUSION}

The goal of this research was to investigate the effects of using gamification to reach company's predetermined goals. The process of the design of the game "Birthday slot machine" using Werbach and Hunter [26] 6 D framework methodology is presented and the results of the game are analyzed to prove the success of the game according the predetermined goals, or to examine the effects of applied gamification measured in the number of acquired new customers, volume of sales and engagement created for a company event. The effects of the application are shown through the increased number of new customers in the period of the game by $318 \%$, increase of the monthly sales by $45 \%$ and awareness created for the company and event that was promoted. A t-test of two independent samples is used to test the hypothesis. To see the impact of the application, the number of new users during the game (15 days) is compared with the number of new users in the previous 15 days. The analysis of the t-test $(p<$ $0,05)$ showed rejection of the null hypothesis and $\mathrm{H} 1$ is proven, i.e. there is a statistically significant difference in the number of new users in the two analyzed periods. The analysis of the t-test $(p<0,05)$ of $\mathrm{H} 2$ showed the rejection of the null hypothesis meaning that the application of gamification can significantly increase the number of sales. In the effort to quantify the results achieved through the game "Birthday Slot Machine", with the main visible purpose for the users being promotion of an event, it can be seen that a clear connection between the virtual gaming space and the offline presence is achieved.

The results of this study can be used by academics and practitioners. It will contribute to the scarce literature on this topic important for marketing and business management. Companies can apply gaming techniques to marketing campaigns, product development efforts, sales activities, or any other business or nonbusiness process. The goals of the game elements being applied must be connected in some well-defined and meaningful way to the business activity so that desired effects and outcomes can be achieved.

The findings of this research are product of case study research made in a small service company acting in the group buying industry (deal marketplace platform). Many 
opportunities for future research on gamification are available. The effectiveness of gamified marketing campaigns and their underlying mechanisms will improve understanding of the specific mechanisms and their impact.

\section{REFERENCES}

[1] Reedy, J.; Schullo, S. and Zimmerman, K.: Electronic Marketing: Integrating Electronic Resources into the Marketing Process.

Dryden Press, Fort Worth, 2000,

[2] Kotler, P. and Keller, K.L.: Marketing Management.

Prentice Hall, New Jersey, 2009,

[3] Hamari, J.; Koivisto, J. and Sarsa, H.: Does Gamification Work? - A Literature Review of Empirical Studies on Gamification.

In proceedings of the 47th Hawaii International Conference on System Sciences, Hawaii, January 6-9, 2014,

[4] Yang, Y.; Asaad, Y. and Dwivedi, Y.: Examining the impact of gamification on intention of engagement and brand attitude in the marketing context.

Computers in Human Behavior 73, 459-469, 2017, http://dx.doi.org/10.1016/j.chb.2017.03.066,

[5] Zichermaim, G. and Cunningham, C.: Gamification by Design: Implementing Game Mechanics in Web and Mobile Apps.

O'Reilly Media, Newton, 2011,

[6] Zichermaim, G. and Linder, J.: The Gamification Revolution: How Leaders Leverage Game Mechanics to Crush the Competition.

McGraw-Hill Education, New York, 2013,

[7] Folmar, D.: Game it up: Using gamification to incentivize your library.

Rowman \& Littlefield, Maryland, 2015,

[8] Francisco-Aparicio, A.; Gutiérrez-Vela, F.L.; Isla-Montes, J.L. and González Sanchez, J.L.: Gamification: Analysis and application.

In: Penichet, V.M.R., Peñalver, A. and Gallud, J.A., eds.: New trends in Interaction, Virtual Reality and Modeling. Human Computer Interaction Series. Springer-Verlag, London, pp.113126, 2013,

[9] McGonigal, J.: Reality is broken: Why games make us better and how they can change the world.

Penguin books, London, 2011,

[10] Schell, J.: The Art of Game Design: A Book of Lenses.

CRC Press, Boca Raton, 2015,

[11] Reeves, B. and Read, J.L.: Total Engagement: Using Games and Virtual Worlds to Change the Way People Work and Businesses Compete.

Harvard Business Press, Harvard, 2009,

[12] Radoff, J.: History of Social Games. http://radoff.com/blog/2010/05/24/history-social-games,

[13] Drucker, P.F.: Management: Tasks, Responsibilities, Practices. Harper \& Row, New York, 1973,

[14] Deterding, S.; Dixon, D.; Khaled, R. and Nacke, L.: From game design elements to gamefulness: Defining gamification.

In: Proceedings of the 15th International Academic MindTrek Conference: Envisioning Future Media Environments. Tampere, 28-30 September 2011,

[15] Huotari, K. and Hamari, J.: A definition for gamification: Anchoring gamification in the service marketing literature.

Electronic Markets 27(1), 21-31, 2016, http://dx.doi.org/10.1007/s12525-015-0212-z, 
[16] Bakker, A.B. and Demerouti, E.: The Job Demand-Resource Model: State of the Art. Journal of Managerial Psychology 22(3), 309-328, 2007, http://dx.doi.org/10.1108/02683940710733115,

[17] Rappaport, S.D.: Lessons from Online Practice: New Advertising Models. Journal of Advertising Research 47, 135-141, 2007, http://dx.doi.org/10.2501/S0021849907070158,

[18] Dick, A.S. and Basu, K.: Customer Loyalty: Toward an Integrated Conceptual Framework. Journal of the Academy of Marketing Science 22, 99-113, 1994, http://dx.doi.org/10.1177/0092070394222001,

[19] Hoyer, W.D. and Brown, S.P.: Effects of Brand Awareness on Choice for a Common, Repeat-Purchase Product.

Journal of Consumer Research 17(2), 141-148, 1990, http://dx.doi.org/10.1086/208544,

[20] Bunchball Inc.: Gamification 101: An Introduction to the Use of Game Dynamics to Influence Behavior. http://www.bunchball.com/gamification/gamification101.pdf,

[21] Hamari, J. and Järvinen, A.: Building Customer Relationship through Game Mechanics in Social Games. 2011,

[22] Witt, M.; Scheiner, C. and Robra-Bissantz, S.: Gamification of Online Idea Competitions: Insights from an Explorative Case. INFORMATIK, Berlin, 2011,

[23] Grouper: Internal Marketing Reports and Statistics. 2013,

[24] National Bank of Republic of Macedonia: Report on the Use of Payment Cards and devices on which they are used in the country. 2013,

[25] Sajtnagodinata: National election of best website of the year. Media Solutions and Keep and eye, Skopje, 2013, http://sajtnagodinata.mk/pages/archive/view.php?y=2011, accessed 30th June 2015,

[26] Werbach, K. and Hunter, K.: For The Win. Wharton Digital Press, Philadelphia, 2012,

[27] Grouper: Internal Marketing Reports and Statistics. 2015. 